\title{
CÁC YẾU TỐ ẢNH HƯởNG ĐẾN Ý ĐỊNH MUA THỰC PHẨM AN TOÀN CỦA NGƯờI TIÊU DÙNG TẠI MỘT SỐ QUẬN TRUNG TÂM TP. HỒ CHÍ MINH
}

\author{
PHẠM XUÂN GIANG, LÊ THANH HÒA \\ Truờng Đại học Công nghiệp Thành phố Hồ Chí Minh \\ phamxuangiang@iuh.edu.vn,lethanhhoa@iuh.edu.vn
}

Tóm tắt: Trong bối cảnh thực phẩm không an toàn được bày bán tràn lan; các vụ ngộ độc thực phẩm vẫn cứ xảy ra thì việc tìm cách gia tăng ý định, sau đó thực hiện hành vi mua thực phẩm an toàn của cư dân TP. Hồ Chí Minh là một việc làm cần thiết. Trên cơ sở khảo sát 230 nguời tiêu dùng tại một số quận trung tâm của thành phố và dữ liệu được xử lý bằng phần mềm SPSS 20. Nghiên cứu đã cho thấy, thực sự có 7 yếu tố ảnh hưởng đến ý định mua thực phẩm an toàn của người tiêu dùng. Đó là: Thái độ đối với môi trường; Sự quan tâm đến sức khỏe; Nhận thức về giá bán; Nhận thức về chất lượng; Sự sẵn có của sản phẩm, Chuẩn chủ quan và Truyền thông đại chúng

Theo đó, 7 hàm ý quản trị được rút ra từ kết quả nghiên cứu. Hy vọng rằng, những hàm ý này, nếu được doanh nghiệp thực hiện, sẽ làm gia tăng ý định mua thực phẩm an toàn của cư dân thành phố.

Từ khóa: Ý định mua, thực phẩm an toàn, người tiêu dùng, TP.Hồ Chí Minh, Cronbach 'Alpha, EFA, Tương quan hồi quy.

\section{FACTORS AFFECTING TO SAFE FOOD PURCHASE INTENTION OF CONSUMERS IN CENTRAL DISTRICT OF HOCHIMINH CITY}

\begin{abstract}
Foods not safe, are sold a lot in street small shops and vendor load. Food poisoning cases are still occurring, consumers of Hochiminh City increase purchase intention, then purchase decision to buy safe food. Basing on the survey of 230 consumers in some central districts of the city. The data was processed using SPSS 20. The study indentified seven factors affecting purchase intention to safe food consist of Attitudes towards the environment; Health consideration; Perceived prices; Perceived Quality; Product availability, Normative and Mass media. Accordingly, 7 managerial implications are derived from the research results. Hopefully, these implications, if implemented by businesses, will increase the purchase intention of safe food of the city residents.
\end{abstract}

Keywords: Purchase intention, safe food, consumers, Ho Chi Minh City, Cronbach's Alpha, EFA, Regression

\section{MỞ ĐẦU}

\subsection{Lý do nghiên cứu}

Thực phẩm là nguồn cung cấp dinh dưỡng để nuôi sống và tạo năng lượng cho hoạt động của con người. Tuy nhiên, sử dụng thực phẩm không an toàn lại là nguồn gốc gây ra bệnh tật, từ đó gây hại cho sức khỏe. Thực phẩm không an toàn được sản xuất, chế biến, bảo quản và sử dụng không hợp lý, đã và đang gây nhiều lo lắng cho người tiêu dùng, cũng như toàn xã hội.

Thời gian gần đây ở thành phố Hồ Chí Minh đã và đang triển khai nhiều giải pháp cần thiết để thực phẩm đem bán ra thị trường phải là thực phẩm an toàn. Trong đó, phải kể đến các giải pháp: Tuyên truyền trên các phương tiện truyền thông đại chúng; Xây dựng đề án chuỗi thực phẩm sạch của thành phố; Thực hiện đề án quản lý, nhận diện và truy xuất nguồn gốc thịt lợn; Xây dựng mô hình chợ thí điểm bảo đảm an toàn thực phẩm....Tuy vậy, tình trạng buôn bán, sử dụng thực phẩm không an toàn vẫn còn dư địa tồn tại trên địa bàn thành phố. Nhiều vụ ngộ độc thực phẩm từ các bếp ăn tập thể, tiệc tùng, đám cuới,...vẫn cứ xảy ra. Hiểm nguy từ các loại thức ăn, nhất là thức ăn đường phố, luôn rình rập mọi người dân sử dụng. Bởi vậy, việc nâng cao ý thức, ý định và mua, sử dụng thực phẩm an toàn của người dân đang là một yêu cầu cấp bách đối với các cấp, các ngành và các nhà khoa học.

\subsection{Mục tiêu nghiên cứu}

- Xác định các yếu tố ảnh hưởng đến ý định mua thực phẩm an toàn

- Đo lường mức độ ảnh hưởng của chúng đến ý định mua thực phẩm an toàn 
- Đề xuất một số hàm ý quản trị cho các doanh nghiệp sản xuất, kinh doanh thực phẩm an toàn nhằm tăng cường ý định mua của người tiêu dùng thành phố Hồ Chí Minh

\subsection{Phương pháp nghiên cứu}

Đề tài sử dụng hai phương pháp nghiên cứu của kinh tế lượng:

- Phương pháp nghiên cứu định tính

Được thực hiện thông qua kỹ thuật thảo luận trực tiếp với 3 chủ cửa hàng thực phẩm an toàn và 7 khách hàng dựa trên một dàn bài được thiết lập trước nhằm khám phá, điều chỉnh, bồ sung thang đo và biến quan sát

- Phương pháp nghiên cứu định luợng, gồm:

Nghiên cứu định lượng sơ bộ: Dữ liệu dùng trong nghiên cứu này được điều tra thuận tiện từ 50 khách hàng, được kiểm định Cronbach's Alpha nhằm mục đích đánh giá sơ bộ thang đo và biến quan sát. Ngoài ra, việc thực hiện buớc nghiên cứu này còn là cơ sở để điều chỉnh từ ngữ, nội dung của bảng hỏi qua việc không hiểu hoặc hiểu không đồng nhất của những khách hàng được điều tra.

Nghiên cứu định lượng chính thức: Được thực hiện bằng phần mềm SPSS 20 trên dữ liệu điều tra từ 226 khách hàng nhằm xác định chính xác yếu tố nào thực sự có ảnh hưởng đến ý định mua thực phẩm an toàn và mức độ ảnh hưởng của chúng. Xuất phát từ kết quả nghiên cứu, các hàm ý quản trị nhằm làm tăng ý định mua thực phẩm an toàn của khách hàng được chỉ ra.

Vì khuôn khổ có giới hạn, nên nội dung của bài báo chỉ được thể hiện kết quả nghiên cứu định lượng chính thức.

\section{NộI DUNG NGHIÊN CÚU}

\subsection{Cơ sở lý thuyết và mô hình nghiên cứu}

\subsubsection{Một số khái niệm căn bản}

\subsubsection{Thực phẩm an toàn}

Luật an toàn thực phẩm của Việt Nam (số 55/2010/QH12) quy định thực phẩm an toàn là thực phẩm không gây hại đến sức khỏe, tính mạng con người ${ }^{(1)}$

Đó là những sản phẩm thông qua hệ thống thiên nhiên để đẩy mạnh vòng quay sinh học và giảm thiểu ô nhiễm môi trường đồng thời cung cấp cho vật nuôi, cây trồng và nông dân một môi trường an toàn và lành mạnh (theo Winter và Davis, 2006);

Thực phẩm an toàn được nuôi trồng và sản xuất trong điều kiện không sử dụng các chất làm màu nhân tạo, thuốc trừ sâu, thuốc tăng trưởng, thuốc tăng trọng cho vật nuôi và các chất biến đổi gen nhằm đảm bảo tính nguyên vẹn của sản phẩm đầu ra (Perry và Schultz,2005; Essoussi và Zahaf, 2008)...

\subsubsection{2 Ý định mua}

Theo Elbeck, 2008, ý định mua được mô tả là sự sẵn sàng của khách hàng trong việc mua sản phẩm. Việc bán hàng của doanh nghiệp có thể được khảo sát dựa trên ý định mua của khách hàng. Dự đoán ý định mua là bước khởi đầu để dự đoán được hành vi mua thực tế của khách hàng (Howard và Sheth, 1967). Từ đó, ý định mua được xem là cơ sở để dự đoán cầu trong tương lai (Warshaw, 1980; Bagozzi, 1983; Fishbein và Ajzen, 1975) ${ }^{(2)}$

\subsubsection{3 Ý định mua thực phẩm an toàn}

Nik Abdul Rashid, 2009, cho rằng, ý định mua thực phẩm an toàn là khả năng và ý chí của cá nhân trong việc dành sự ưa thích của mình cho thực phẩm an toàn hơn là thực phẩm thường trong việc cân nhắc mua sắm. Han, Hsu và Lee, 2009, lại cho rằng ý định mua thực phẩm an toàn thường gắn với những lời truyền miệng tốt về sản phẩm và ý định trả nhiều tiền hơn cho sản phẩm an toàn; ...

\subsubsection{Cơ sở lý thuyết}

Lý thuyết hành vi hợp lý (TRA) được xây dựng bởi Ajzen và Fishbein vào năm 1975 và lý thuyết hành vi có kế hoạch (TPB) được phát triển bởi Ajzen vào năm 1991 là cơ sở lý thuyết cho vấn đề nghiên cứu ${ }^{(3)}$. Tương tự, đã có nhiều nghiên cứu về hành vi "ý định" mua thực phẩm an toàn được thực hiện trên cơ sở của hai lý thuyết này. Điển hình là: 
- Nghiên cứu của Nguyễn Phong Tuấn (2011) về ý định mua thực phẩm an toàn với 6 thang đo độc lập. Đó là thái độ đối với môi trường, nhận thức về chất lượng, sự quan tâm tới sức khỏe, hiểu biết về thực phẩm an toàn, chuẩn chủ quan và thái độ đối với thực phẩm an toàn;

- Nghiên cứu của Nguyễn Thanh Hương (2012) với 3 thang đo độc lập là niềm tin, nhận thức về giá và hình thức sản phẩm;

- Nghiên cứu của Lê Thùy Hương (2014) đã chỉ ra có 9 thang đo độc lập ảnh hưởng đến ý định mua thực phẩm an toàn của cư dân TP.Hà Nội là sự quan tâm đến sức khỏe, nhận thức về chất luợng, sự quan tâm đến môi trường, chuẩn mực chủ quan, nhận thực về sự sã̃n có của sản phẩm, nhận thức về giá bán, tham khảo-thông tin, tham khảo-tuân thủ, tham khảo-giá trị bản thân, truyền thông đại chúng(4)

- Nghiên cứu của Anssi Tarkiainen và Sanna Sundqvist tại Phần Lan (2005) đã xem xét mối quan hệ giữa sự quan tâm đến sức khỏe, thái độ đối với nông sản hữu cơ, chuẩn mực chủ quan, nhận thức về giá bán và nhận thức về sự sẵn có của sản phẩm tới ý định mua thực phẩm an toàn, từ đó ảnh hưởng đến mức độ thường xuyên mua thực phẩm an toàn;

- Nghiên cứu của Jay Dickieson và Victoria Arkus tại Anh (2009) với 5 thang đo độc lập. Kết quả nghiên cứu chỉ ra rằng sự quan tâm đến sức khỏe, nhận thức về chất lượng, sự tin tưởng vào nhãn hiệu nông sản hữu cơ, sự quan tâm tới an toàn thực phẩm và giá cả đều có ảnh hưởng đến ý định mua của người tiêu dùng;

- Nghiên cứu của Victoria Kulikovski và Manjola Agolli tại Hi Lạp (2010) với 6 thang đo độc lập. Đó là sự quan tâm tới sức khỏe, nhận thức về chất lượng, nhận thức về giá trị, sự quan tâm tới an toàn thực phẩm, sự quan tâm tới đạo đức và giá bán;...

Thang đo độc lập của các nghiên cứu trên đây khá thống nhất. Chúng đều bao gồm: Sự quan tâm đến sức khỏe; Thái độ đối với môi trường; Nhận thức về chất lượng; Chuẩn chủ quan; Sự sẵn có của sản phẩm và Nhận thức về giá bán.

\subsubsection{Mô hình nghiên cứu, giả thuyết nghiên cứu và biến quan sát}

\subsubsection{Mô hình nghiên cứu}

Tham khảo mô hình của các nghiên cứu trên đây kết hợp với sự phân tích thực tế tại TP. Hồ Chí Minh, mô hình nghiên cứu được xác định gồm 7 thang đo độc lập:

\section{a) Sự quan tâm đến sức khỏe}

Sức khỏe được định nghĩa là trạng thái tốt của thể lực, trí lực và sự hạnh phúc. Để đạt được mục tiêu này, người tiêu dùng luôn quan tâm đển sức khỏe của bản thân, tìm kiếm, mua và àn các loại thực phẩm sạch, bổ dưỡng, tham gia chơi thể dục, thể thao. Chính vì vậy, yếu tố này được nhóm tác giả sử dụng trong nghiên cứu

\section{b) Nhận thức về chất lượng}

Khái niệm về chất lượng thực phẩm an toàn liên quan đến những yếu tố thuộc cảm giác như vị của thực phẩm, kinh nghiệm tiểu dùng thực phẩm, sự thưởng thức thực phẩm (Magnusson, 2001).Vấn đề chất lượng thực phẩm an toàn vẫn là vấn đề được nhiều nhà nghiên cứu cho là có ảnh hưởng quan trọng đến hành vi thực phẩm an toàn. Vì vậy, đây là yếu tố thứ hai được chọn đề đưa vào mô hình nghiên cứu

\section{c) Thái độ đối với môi truò̀ng}

Kalafatis Pollard, East và Tsogas (1999) mô tả thái độ đối với môi trường là sự thức tỉnh và nhận thức của người tiêu dùng về việc môi trường đang bị đe dọa và tài nguyên thiên nhiên đang ngày càng cạn kiệt. Sự quan tâm đến môi trường là niềm tin, thái độ quan điểm và mức độ bận tâm của cá nhân đổi với môi trường. Điều đó liên quan đển ý định mua thực phẩm của người tiêu dùng, bởi vì sản xuất và sử dụng thực phẩm an toàn có tác dụng bảo vệ môi trường.

\section{d) Chuẩn chủ quan}

Chuẩn chủ quan được hiểu như là sự ảnh hưởng của các yếu tố bên ngoài, trước hết là hành động và lời khuyên của bạn bè, người thân, người nổi tiếng hoặc các nhóm tham khảo khác đến người tiêu dùng. Điều đó làm nảy sinh nơi người tiêu dùng một ý định hành vi cụ thể, ở đây là ý định mua và sử dụng thực phẩm an toàn

\section{e) Nhận thức về giá bán}


Giá là số tiền người mua phải trả để có được sản phẩm hay dịch vụ (Philip Kotler và cộng sự, 2001). Người tiêu dùng thường có nhận thức là giá thực phẩm an toàn cao hơn giá thực phẩm thường (Magnusson và cộng sự, 2001) và họ sẵn lòng chấp nhận điều đó. Không thể nào có chuyện giá thực phẩm an toàn lại thấp hơn hay ngang bằng với giá của thực phẩm thường. Bởi vậy, giá thực phẩm an toàn cao tương đối có tác động đến ý định mua và hành vi mua của người tiêu dùng

\section{f) Sụ̂ sắn có của sản phẩm}

Nhiều khi người tiêu dùng có ý định mua thực phẩm an toàn, nhưng vì các siêu thị, cửa hàng,.. không sẵn có loại thực phẩm này hoặc nằm ở những nơi quá xa làm cho họ triệt tiêu ý định. Sự có mặt của thực phẩm an toàn trong các hệ thống siêu thị, trong các cửa hàng bán lẻ truyền thống và có vị trí thuận lợi đã làm gia tăng khả năng tiếp cận của người tiêu dùng (Dettmann và Dimitri, 2007). Chính vì vậy, sự sẵn có của thực phẩm an toàn ảnh hưởng đến ý định mua và sử dụng của người tiêu dùng về loại sản phẩm này

\section{g) Truyền thông đại chúng}

Mặc dù yếu tố "Truyền thông đại chúng" được khá ít nghiên cứu sử dụng, nhưng xét thấy TP. Hồ Chí Minh có mạng lưới thông tin đại chúng phát triển và bao phủ, vì vậy yếu tố này đã được nhóm tác giả lựa chọn để đưa vào mô hình nghiên cứu chính thức.

Truyền thông đại chúng bằng nhiều hình thức khác nhau có ảnh hưởng rõ ràng tới ý thức của con người. Truyền thông giúp người tiêu dùng biết và hiểu tác dụng của thực phẩm an toàn, nơi mua và cơ sở sản xuất, giá cả và chất lượng sản phẩm...

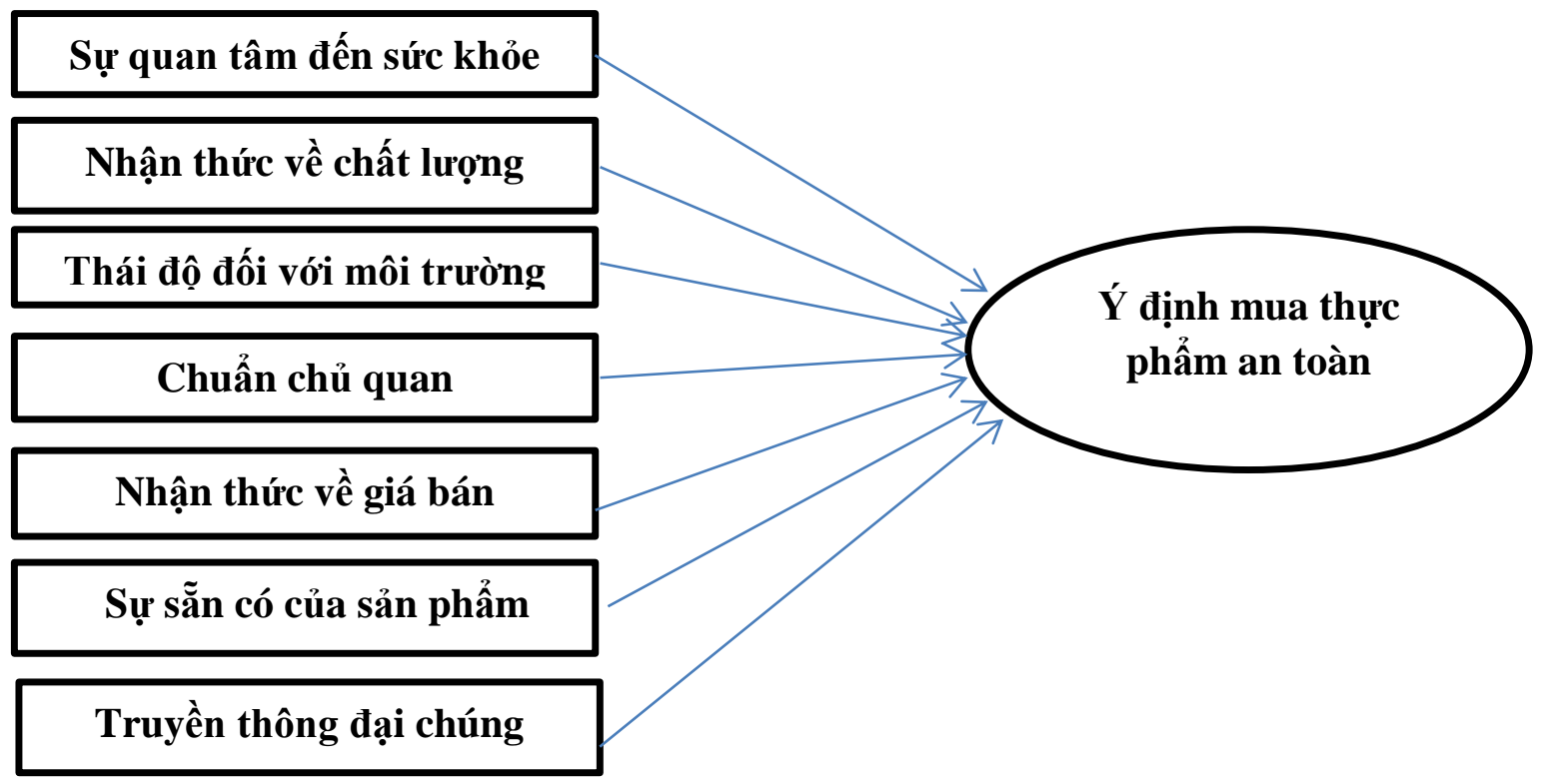

Hình 1: Mô hình nghiên cứu chính thức

\subsubsection{Giả thuyết nghiên cứu}

\section{Có 7 giả thuyết nghiên cứu được xác định:}

- H1: Sự quan tâm sức khỏe có tác động thuận chiều đến ý định mua thực phẩm an toàn

- H2: Nhận thức về chất lượng sản phẩm có tác động thuận chiều tới ý định mua thực phẩm an toàn

- H3: Thái độ đối với môi trường có tác động thuận chiều đến ý định mua thực phẩm an toàn.

- H4: Chuẩn mực chủ quan có tác động thuận chiều đến ý định mua thực phẩm an toàn.

- H5: Nhận thức về giá bán có ảnh hưởng thuận chiều đến ý định mua thực phẩm an toàn.

- H6: Nhận thức về sự sẵn có của sản phẩm tác động thuận chiều đến ý định mua thực phẩm an toàn.

- H7: Truyền thông đại chúng ảnh hưởng thuận chiều tới ý định mua thực phẩm an toàn.

\subsubsection{Thang đo và biến quan sát}

Sau buớc nghiên cứu định lượng sơ bộ đã có ba biến quan sát bị loại vì có hệ số tương quan biến tổng <0.3, đó là các biến:

- Thực phẩm an toàn được đóng gói và vận chuyển thân thiện với môi trường (MT5) 
- Có nhiều thực phẩm an toàn để lựa chọn (SSC4)

- Thực phẩm an toàn có thể được mua trực tuyến thuận lợi (SSC5)

Các biến còn lại được hiệu chỉnh và mã hóa như trong bảng 1 .

Bảng 1: Mã hóa thang đo và biến quan sát của thang đo

\begin{tabular}{|c|c|c|}
\hline STT & CÁC THANG ĐO VÀ BIẾN QUAN SÁT & М̃̃ HÓA \\
\hline I. & Sự quan tâm đến sức khỏe & SK \\
\hline 01 & Thực phẩm an toàn chứa nhiều dinh dưỡng & SK1 \\
\hline 02 & Sử dụng thực phẩm an toàn có lợi cho sức khỏe & SK2 \\
\hline 03 & Sử dụng thực phẩm an toàn đảm bảo sức khỏe cho bé lớn nhanh & SK3 \\
\hline 04 & Sử dụng thực phẩm an toàn có thể kéo dài tuổi thọ & SK4 \\
\hline 05 & Sử dụng thực phẩm an toàn giúp phòng ngừa được bệnh tật & SK5 \\
\hline II. & Thái độ đối với môi trường & MT \\
\hline 06 & Sử dụng thực phẩm an toàn góp phần bảo vệ môi trường & MT1 \\
\hline 07 & Chất thải từ thực phẩm an toàn không gây ô nhiễm môi trường & MT2 \\
\hline 08 & Sản xuất và chế biến thực phẩm an toàn không gây ô nhiễm & MT3 \\
\hline 09 & Sản xuất thực phẩm an toàn sử dụng ít năng lượng nhân tạo & MT4 \\
\hline III. & Nhận thức về chất lượng & $\mathbf{C L}$ \\
\hline 10 & Thực phẩm an toàn là thực phẩm có chất lượng tốt & CL1 \\
\hline 11 & Thực phẩm an toàn có chất lượng cao hơn thực phẩm thường & CL2 \\
\hline 12 & Chất lượng của thực phẩm an toàn luôn được đảm bảo & CL3 \\
\hline 13 & Chất lượng của thực phẩm an toàn đang ngày được nâng cao & CL4 \\
\hline IV. & Chuẩn chủ quan & CCQ \\
\hline 14 & Những người trong gia đình khuyên tôi dùng thực phẩm an toàn & CCQ1 \\
\hline 15 & Bạn bè tôi khuyên tôi dùng thực phẩm an toàn & CCQ2 \\
\hline 16 & Đồng nghiệp tôi khuyên tôi dùng thực phẩm an toàn & CCQ3 \\
\hline 17 & Những người tôi tham khảo khuyên tôi dùng thực phẩm an toàn & CCQ4 \\
\hline V. & Nhận thức về sự sẵn có của sản phẩm & SSC \\
\hline 18 & Thực phẩm an toàn dễ dàng tìm thấy nơi tôi sinh sống & SSC1 \\
\hline 19 & Thực phẩm an toàn luôn có sẵn ở các siêu thị, cửa hàng và chợ & SSC2 \\
\hline 20 & Tại những nơi này thực phẩm an toàn được để ở vị trí dễ tìm kiếm & SSC3 \\
\hline VI. & Nhận thức về giá bán của sản phẩm & GB \\
\hline 21 & Thực phẩm an toàn có giá bán cao hợp lý so với thực phẩm thường & GB1 \\
\hline 22 & Giá bán của thực phẩm an toàn tương xứng với chất lượng & GB2 \\
\hline 23 & Giá bán của thực phẩm an toàn phù hợp với khả năng chi trả của tôi & GB3 \\
\hline VII. & Truyền thông đại chúng & TT \\
\hline 24 & Thực phẩm an toàn được quảng cáo và giới thiệu trên tivi & TT1 \\
\hline 25 & Thực phẩm an toàn được quảng cáo và giới thiệu trên Internet & TT2 \\
\hline 26 & Thực phẩm an toàn được quảng cáo và giới thiệu trên báo, tạp chí & TT3 \\
\hline \multirow[t]{2}{*}{27} & Thực phẩm an toàn được quảng cáo và giới thiệu trên radio & TT4 \\
\hline & $\dot{Y}$ định mua thực phẩm an toàn & YDM \\
\hline 28 & Tôi sẽ mua các loại thực phẩm an toàn trong thời gian tới & YDM1 \\
\hline 29 & Tôi sẽ mua thực phẩm an toàn thường xuyên & YDM2 \\
\hline 30 & Tôi có ý định mua thực phẩm an toàn do có lợi cho sức khỏe & YDM3 \\
\hline 31 & Tôi sẽ giới thiệu thực phẩm an toàn với bạn bè tôi & YDM4 \\
\hline 32 & Tôi có ý định mua thực phẩm an toàn vì môi trường & YDM5 \\
\hline
\end{tabular}

Nguồn: Tổng hợp và bổ sung của nhóm tác giả

Tóm lại: Tổng số biến quan sát được đưa vào nghiên cứu định lượng chính thức là 27 của 7 thang đo độc lập và 5 biến của thang đo phụ thuộc. 


\subsection{Kết quả nghiên cứu}

\subsubsection{Kích thước và cơ cấu mẫu}

Kích thước mẫu: Theo Hair \& ctg (2006) (được trích bởi Nguyễn Đình Thọ \& ctg, 2011) thì kích thước mẫu tối thiểu phải là 100 với tỷ lẹ̣ $5: 1$ (nghĩa là 1 biến quan sát cần tối thiểu 5 đơn vị điều tra) ${ }^{(5)}$. Mô hình của nghiên cứu có 32 biến quan sát, vì vậy kích thước mẫu tối thiểu được xác định là $32 * 5=160$ Tuy nhiên, để tăng độ chính xác và đề phòng có phiếu điều tra không hợp lệ phải loại bỏ, kích thước mẫu của nghiên cứu này được chọn là 230 khách hàng, tương ứng có 230 bảng hỏi được phát ra. Kết quả có 226 bảng hỏi hợp lệ, chiếm 98,26\%. Mẫu được chọn theo phương pháp phi xác suất với hình thức thuận tiện có khống chế số lượng phiếu điều tra cho từng quận: $1,3,5$, Phú Nhuận và Tân Bình tương ứng là $50,50,50$, 50 và 30 phiếu.

Cơ cấu mẫu theo giới tính: nam chiếm $34,5 \%$, nữ $65,5 \%$; Theo độ tuổi: từ 18 - dưới 25 tuổi $12,8 \%$, từ 25- dưới 35 tuổi $35,8 \%$, từ 35 - dưới 55 tuổi: $48,7 \%$ và từ 55 tuổi trở lên chiếm $2,7 \%$; Theo thu nhập bình quân: dưới 5 triệu đồng/người/tháng chiếm $4,4 \%$, từ 5 - dưới 10 triệu $8,8 \%$, từ 10 - dưới 15 triệu $22,1 \%$ và từ 15 triệu đồng trở lên là 64,6\%. Qua đây cho thấy: Khách hàng nữ, khách hàng có độ tuổi trung niên và khách hàng có thu nhập cao mua thực phẩm an toàn nhiều hơn các loại khách hàng khác.

\subsubsection{Giá trị trung bình của các thang đo độc lập và biến quan sát}

Trong thống kê mô tả, giá trị trung bình của các biến quan sát thuộc thang đo độc lập là thông tin quan trọng dùng để thiết kế nội dung của các hàm ý quản trị

Bảng 2: Giá trị trung bình của biến quan sát thuộc 7 thang đo độc lập

\begin{tabular}{|c|c|c|c|c|c|}
\hline $\begin{array}{l}\text { Thang đo và } \\
\text { biến quan sát }\end{array}$ & $\begin{array}{l}\text { Giá trị trung } \\
\text { bình }\end{array}$ & $\begin{array}{c}\text { Thang đo và } \\
\text { biến quan sát } \\
\text { (tiếp theo) }\end{array}$ & $\begin{array}{l}\text { Giá trì trung } \\
\text { bình } \\
\text { (tiếp theo) }\end{array}$ & $\begin{array}{c}\text { Thang đo và } \\
\text { biến quan sát } \\
\text { (tiếp theo) }\end{array}$ & $\begin{array}{l}\text { Giá trị trung } \\
\text { bình } \\
\text { (tiếp theo) }\end{array}$ \\
\hline $\begin{array}{l}\text { I. SK } \\
\text { 1. SK1 } \\
\text { 2. SK2 } \\
\text { 3. SK3 } \\
\text { 4. SK4 } \\
\text { 5. SK5 }\end{array}$ & $\begin{array}{l}3,86 \\
3,88 \\
3,96 \\
3,94 \\
3,90 \\
\end{array}$ & $\begin{array}{l}\text { IV.CCQ } \\
14 \cdot C C Q 1 \\
\text { 15. CCQ2 } \\
\text { 16. CCQ3 } \\
\text { 17. CCQ4 }\end{array}$ & $\begin{array}{l}3,84 \\
3,96 \\
3,89 \\
3,87\end{array}$ & $\begin{array}{l}\frac{\text { VII. TT }}{24 . \text { TT1 25.TT2 }} \\
\text { 26. TT3 } \\
\text { 27.TT4 }\end{array}$ & $\begin{array}{l}3,79 \\
3,86 \\
3,59 \\
3,76\end{array}$ \\
\hline $\begin{array}{l}\text { II. MT } \\
6 . \mathrm{MT} 1 \\
\text { 7. MT2 } \\
\text { 8. MT3 } \\
\text { 9. MT4 }\end{array}$ & $\begin{array}{l}3,87 \\
3,93 \\
3,81 \\
4,07 \\
\end{array}$ & $\begin{array}{l}\text { V.SSC } \\
\text { 18. SSC } 1 \\
\text { 19. SSC2 } \\
\text { 20. SSC3 }\end{array}$ & $\begin{array}{l}3,70 \\
3,85 \\
3,74\end{array}$ & & \\
\hline $\begin{array}{l}\underline{\text { III. CL }} \\
10 . \text { CL1 } \\
\text { 11.CL2 12.CL3 } \\
\text { 13.CL4 }\end{array}$ & $\begin{array}{l}3,96 \\
3,94 \\
4,08 \\
4,00\end{array}$ & $\begin{array}{l}\text { VI.GB } \\
\text { 21. GB1 } \\
\text { 22. GB2 } \\
\text { 23. GB3 }\end{array}$ & $\begin{array}{l}3,86 \\
4,03 \\
4,10\end{array}$ & & \\
\hline
\end{tabular}

Nguồn: Tính toán của nhóm tác giả

\subsubsection{Kiểm định Cronbach's alpha}

Kiểm định Cronbach's Alpha với mục đích là loại bỏ các thang đo và biến quan sát không đạt tiêu chuẩn. Cụ thể: (1)Thang đo bị loại khỏi mô hình nghiên cứu khi có hệ số Cronbach's Alpha <0.6; và (2)Biến quan sát bị loại khỏi thang đo khi có hệ số tương quan biến tổng < 0.3 hoặc có hệ số Cronbach alpha của biến đó> hệ số Cronbach'alpha của thang đo ${ }^{(6)}$

\section{a) Kiểm định Cronbach's Alpha cho các thang đo độc lập}

Trong 7 thang đo độc lập có 6 thang đo chỉ phải kiểm định Cronbach's Alpha một lần. Thang đo còn lại là "Thái độ đối với môi trường-MT" phải kiểm định lần hai. Theo đó, lần 1 thang đo này có hệ số Cronbach's Alpha là $0.732>0.6$, nhưng có biến "Sử dụng thực phẩm an toàn góp phần bảo vệ môi trường- 
MT1" có hệ số tương quan biến tổng là $0.285<0.3$ bị loại khỏi mô hình. Kết quả kiểm định lần 2 làm cho hệ số Cronbach alpha của thang đo này tăng lên thành 0.817 .

b) Kiểm định Cronbach's Alpha cho thang đo phụ thuộc

Sau kiểm định lần 1, thang đo phụ thuộc "Ý định mua thực phẩm an toàn-YDM" có hệ số Cronbach's Alpha là $0.830>0.6$, đồng thời cả 5 biến quan sát đều đạt yêu cầu để đưa vào bước phân tích tiếp theo.

Tóm lại: Sau buớc kiểm định Cronbach's Alpha, biến quan sát của các thang đo độc lập còn lại 26, số biến quan sát của thang đo phụ thuộc vẫn là 5 biến. Kết quả như sau:

Bảng 3: Kết quả kiểm định Cronbach’s Alpha

\begin{tabular}{|c|l|c|c|c|}
\hline STT & \multicolumn{1}{|c|}{ Tên thang đo } & $\begin{array}{c}\text { Số biến } \\
\text { quan sát còn lại }\end{array}$ & $\begin{array}{c}\text { Hệ số Cronbach's } \\
\text { Alpha }\end{array}$ & $\begin{array}{c}\text { Biến } \\
\text { bị loại }\end{array}$ \\
\hline 1 & Sự quan tâm đến sức khỏe (SK) & 5 & 0.841 & \\
\hline 2 & Thái độ đối với môi trường (MT) & 3 & 0.817 & MT1 \\
\hline 3 & Nhận thức về chất lượng (CL) & 4 & 0.775 & \\
\hline 4 & Chuẩn chủ quan (CCQ) & 4 & 0.810 & \\
\hline 5 & Nhận thức về sự sẵn có (SSC) & 3 & 0.701 & \\
\hline 6 & Nhận thức về giá bán (GB) & 3 & 0.751 & \\
\hline 7 & Truyền thông đại chúng (TT) & 4 & 0.791 & \\
\hline & Ý $Đ I N H M U A(Y D M)$ & 5 & 0.830 & \\
\hline
\end{tabular}

Nguồn: Kết quả nghiên cứu của tác giả

\subsubsection{Phân tích nhân tố khám phá (EFA)}

Mục đích của phân tích này là nhằm loại những biến quan sát có hệ số tải nhân tố (factor loading) nhỏ hơn 0.5 và kiểm tra độ lớn của phương sai trích ${ }^{(6)}$

\section{a) Phân tích EFA cho thang đo độc lập}

Bảng 4: KMO and Bartlett's Test

\begin{tabular}{|l|l|l|}
\hline Kaiser-Meyer-Olkin Measure of Sampling Adequacy. & .816 \\
\hline \multirow{3}{*}{ Bartlett's Test of Sphericity } & Approx. Chi-Square & 2568.010 \\
\cline { 2 - 3 } & df & 325 \\
\cline { 2 - 3 } & Sig. & .000 \\
\hline
\end{tabular}

Bảng 5: Total Variance Explained

\begin{tabular}{|l|l|l|l|l|c|c|c|c|c|}
\hline Component & \multicolumn{3}{|c|}{ Initial Eigenvalues } & \multicolumn{3}{c|}{$\begin{array}{c}\text { Extraction Sums of Squared } \\
\text { Loadings }\end{array}$} & \multicolumn{3}{|c|}{$\begin{array}{c}\text { Rotation Sums of Squared } \\
\text { Loadings }\end{array}$} \\
\cline { 2 - 11 } & Total & $\begin{array}{c}\text { \% of } \\
\text { Variance }\end{array}$ & $\begin{array}{c}\text { Cumulative } \\
\%\end{array}$ & Total & $\begin{array}{c}\text { \% of } \\
\text { Variance }\end{array}$ & $\begin{array}{c}\text { Cumulative } \\
\%\end{array}$ & Total & $\begin{array}{c}\% \text { of } \\
\text { Variance }\end{array}$ & $\begin{array}{c}\text { Cumulative } \\
\%\end{array}$ \\
\hline 1 & 6.847 & 26.333 & 26.333 & 6.847 & 26.333 & 26.333 & 3.264 & 12.552 & 12.552 \\
\hline 2 & 2.974 & 11.438 & 37.771 & 2.974 & 11.438 & 37.771 & 2.834 & 10.901 & 23.453 \\
\hline 3 & 2.112 & 8.124 & 45.895 & 2.112 & 8.124 & 45.895 & 2.717 & 10.449 & 33.903 \\
\hline 5 & 1.686 & 6.484 & 52.379 & 1.686 & 6.484 & 52.379 & 2.367 & 9.104 & 43.006 \\
\hline 6 & 1.446 & 5.563 & 57.942 & 1.446 & 5.563 & 57.942 & 2.276 & 8.754 & 51.760 \\
\hline 7 & 1.246 & 4.792 & 62.734 & 1.246 & 4.792 & 62.734 & 2.012 & 7.739 & 59.499 \\
\hline & 1.120 & 4.306 & 67.040 & 1.120 & 4.306 & 67.040 & 1.961 & 7.541 & 67.040 \\
\hline 25 & $\ldots$ & $\ldots$ & $\ldots$ & $\ldots$ & $\ldots$ & $\ldots$ & $\ldots$ & $\ldots$ & $\ldots$ \\
\hline 26 & .193 & .741 & 99.344 & & & & & & \\
\hline
\end{tabular}

Extraction Method: Principal Component Analysis. 
- Hệ số KMO bằng $0.816>0.5$ nên phân tích nhân tố là phù hợp với dữ liệu thực tế.

- Kiểm định Bartlett có giá trị sig $=0.000<0.05$ chứng tỏ các biến quan sát có tương quan với nhau trong tổng thể.

- Tại mức giá trị Eigenvalue 1,120>1 của phương pháp trích Principal Components, đã rút trích được 7 nhân tố từ 26 biến quan sát.

- Phương sai trích là $67,040 \%>50 \%$, thể hiện rằng $67,040 \%$ sự biến thiên của dữ liệu được giải thích bởi 07 nhân tố này.

Bảng 6: Rotated Component Matrix ${ }^{\mathrm{a}}$

\begin{tabular}{|c|c|c|c|c|c|c|c|}
\hline & Comp & & & & & & \\
\hline & 1 & 2 & 3 & 4 & 5 & 6 & 7 \\
\hline SK1 & .831 & & & & & & \\
\hline SK4 & .776 & & & & & & \\
\hline SK5 & .700 & & & & & & \\
\hline SK2 & .695 & & & & & & \\
\hline SK3 & .672 & & & & & & \\
\hline CQ2 & & .805 & & & & & \\
\hline CQ1 & & .753 & & & & & \\
\hline CQ4 & & .748 & & & & & \\
\hline CQ3 & & .681 & & & & & \\
\hline TT4 & & & .812 & & & & \\
\hline TT1 & & & .769 & & & & \\
\hline TT2 & & & .753 & & & & \\
\hline TT3 & & & .732 & & & & \\
\hline MT2 & & & & .861 & & & \\
\hline MT3 & & & & .745 & & & \\
\hline MT4 & & & & .703 & & & \\
\hline CL1 & & & & & .807 & & \\
\hline CL2 & & & & & .774 & & \\
\hline CL3 & & & & & .660 & & \\
\hline CL4 & & & & & .531 & & \\
\hline GB1 & & & & & & .811 & \\
\hline GB3 & & & & & & .774 & \\
\hline GB2. & & & & & & .666 & \\
\hline SSC1. & & & & & & & .797 \\
\hline SSC3. & & & & & & & .761 \\
\hline SSC2. & & & & & & & .729 \\
\hline
\end{tabular}

Extraction Method: Principal Component Analysis.

Rotation Method: Varimax with Kaiser Normalization.

a. Rotation converged in 6 iterations.

Nguồn: Kết quả nghiên cứu của tác giả

\section{b) Phân tích EFA cho thang đo phụ thuộc}

Thực hiện phân tích EFA tương tự như đối với các thang đo độc lập, thang đo phụ thuộc "Ý định muaYDM" có kết quả:

- Hệ số KMO bằng $0.734>0.5$ nên phân tích nhân tố là phù hợp với dữ liệu thực tế.

- Kiểm định Bartlett có giá trị sig $=0.000<0.05$, chứng tỏ các biến quan sát có tương quan với nhau trong tổng thể.

- Tại mức giá trị Eigenvalue 2.986>1 của phương pháp trích Principal Components, đã rút trích được 1 nhân tố từ 5 biến quan sát.

- Phương sai trích là 59.721\%>50\%, thể hiện 59.721\% sự biến thiên của dữ liệu được giải thích bởi 1 nhân tô. 
Tóm lại: Kết quả phân tích EFA cho thấy, tất cả các hệ số tải nhân tố của biến quan sát đều lớn hơn 0.5 và có 7 biến tổng được tạo ra khi phân tích cho thang đo độc lập và có 1 biến tổng của thang đo phụ thuộc là ý định mua thực phẩm an toàn (YDM). Do đó, mô hình hiệu chỉnh sau EFA là:

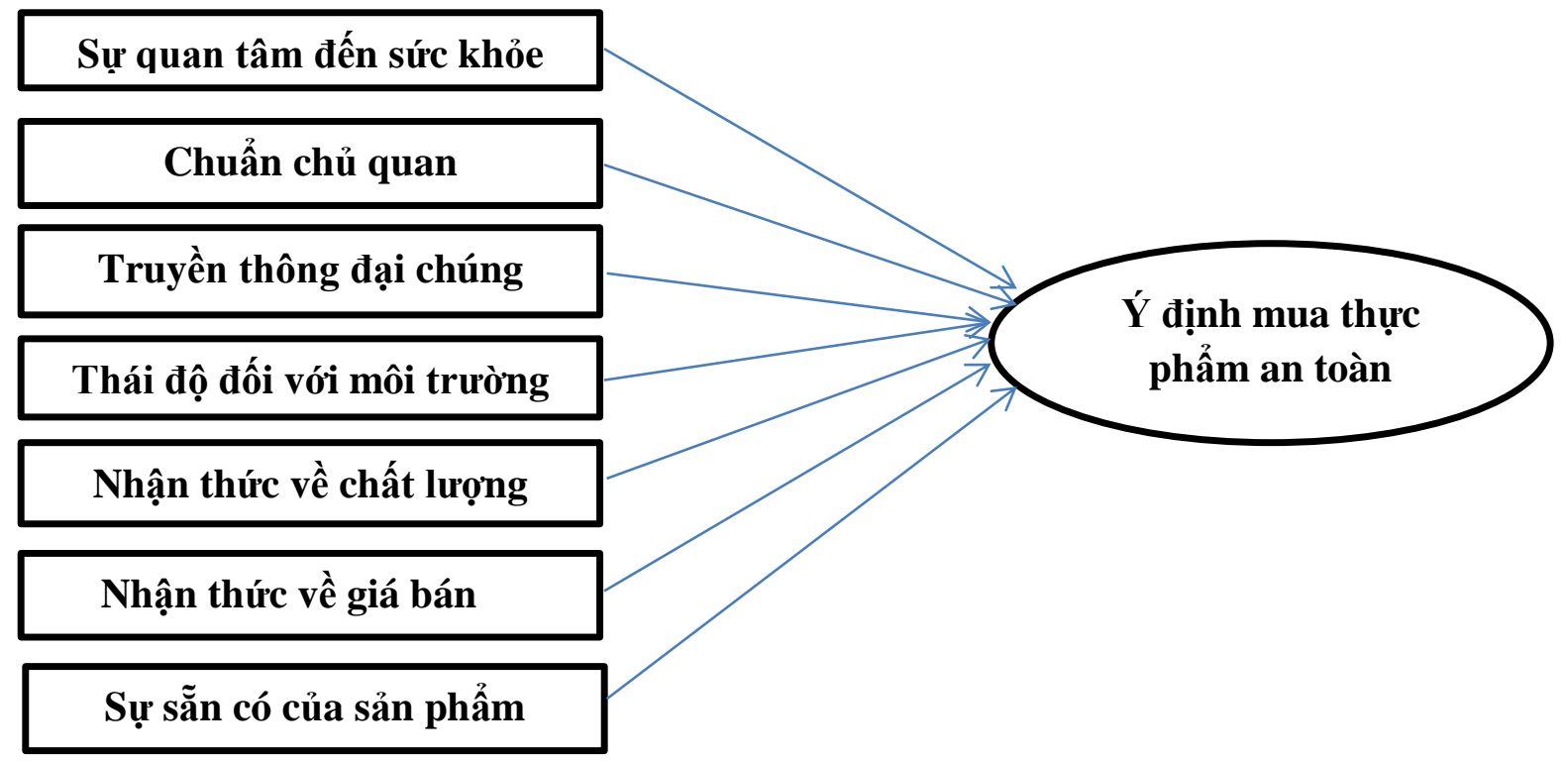

Hình 2: Mô hình nghiên cứu hiệu chỉnh

\subsubsection{Phân tích hồi quy đa biến}

\section{a) Phân tích tưong quan}

Kết quả trong bảng Correlations cho thấy: các biến độc lập đều có quan hệ tương quan với biến phụ thuộc với mức ý nghĩa Sig. $<0.05$. Trong đó, biến "Thái độ đối với môi trường" có hệ số tương quan mạnh nhất $(65,0 \%)$ và biến "Truyền thông đại chúng" có hệ số tương quan yếu nhất $(23,5 \%)$ với biến "Ý định mua”. Đồng thời, qua bảng này cũng bước đầu cho biết, không có hiện tượng đa cộng tuyến giữa các biến độc lập. Bởi vì hệ số tương quan của từng cặp biến giữa chúng đều nhỏ hơn $80 \%$

b) Kiểm định độ phù họ̣p của mô hình

Bảng 7: ANOVA $^{\mathrm{a}}$

\begin{tabular}{|c|c|c|c|c|c|c|}
\hline \multicolumn{2}{|c|}{ Model } & Sum of Squares & df & Mean Square & F & Sig. \\
\hline \multirow{4}{*}{} & Regression & 33.881 & 7 & 4.840 & 59.432 & $.000^{\mathrm{b}}$ \\
\cline { 2 - 7 } & Residual & 17.754 & 218 & .081 & & \\
\cline { 2 - 7 } & Total & 51.635 & 225 & & & \\
\hline
\end{tabular}

Nguồn: Tính toán của tác giả

Bảng trên cho thấy: $F=59.432$ và $\mathrm{Sig}=0.000<0.05$ chứng tỏ mô hình lý thuyết phù hợp với thực tế, các biến độc lập có tương quan tuyến tính với biến phụ thuộc

c) Đánh giá độ phù họ̣p của mô hình

Bảng 8: Giá trị của các hệ số xác định

\begin{tabular}{|c|c|c|c|c|c|}
\hline Mô hình & $\mathrm{R}$ & $\begin{array}{c}\text { R bình } \\
\text { phương }\end{array}$ & $\begin{array}{c}\text { R bình phương hiệu } \\
\text { chỉnh }\end{array}$ & $\begin{array}{c}\text { Sai số chuẩn ước } \\
\text { lượng }\end{array}$ & Hệ số Durbin-Watson \\
\hline 1 & $.810^{\mathrm{a}}$ & .656 & .645 & .285 & 2.082 \\
\hline
\end{tabular}

Nguồn: Tính toán của tác giả 
Bảng 8 cho thấy độ phù hợp của mô hình là khá tốt với $\mathrm{R}=0.810, \mathrm{R}^{2}=0.656$ và $\mathrm{R}^{2}$ hiệu chỉnh $=$ 0.656. Điều này chứng tỏ $65,6 \%$ "Ý định mua thực phẩm an toàn" được giải thích bởi 7 biến độc lập. Đồng thời mô hình không có hiện tượng tự tương quan vì hệ số Durbin-Watson $(\mathrm{d}=2.082)$ nằm trong khoảng 1-3.

d) Hồi quy bội

Bảng 9: Coefficients ${ }^{\mathrm{a}}$

\begin{tabular}{|c|c|c|c|c|c|c|c|c|c|c|}
\hline \multirow{2}{*}{\multicolumn{2}{|c|}{ Model }} & \multicolumn{2}{|c|}{$\begin{array}{l}\text { Unstandardized } \\
\text { Coefficients }\end{array}$} & \multirow{2}{*}{\begin{tabular}{|c|}
$\begin{array}{c}\text { Standardized } \\
\text { Coefficients }\end{array}$ \\
$\mathrm{r}$
\end{tabular}} & \multirow[t]{2}{*}{$\mathrm{t}$} & \multirow[t]{2}{*}{ Sig. } & \multicolumn{2}{|c|}{$\begin{array}{c}95.0 \% \text { Confidence } \\
\text { Interval for B }\end{array}$} & \multicolumn{2}{|c|}{$\begin{array}{c}\text { Collinearity } \\
\text { Statistics }\end{array}$} \\
\hline & & B & Std. Error & & & & $\begin{array}{l}\text { Lower } \\
\text { Bound }\end{array}$ & $\begin{array}{l}\text { Upper } \\
\text { Bound }\end{array}$ & Tolerance & VIF \\
\hline \multirow{8}{*}{1} & (Constant & -.048 & .219 & & .220 & 826 & -.479 & 383 & & \\
\hline & SK & .181 & .040 & 220 & 4.501 & .000 & 101 & 260 & 659 & 1.517 \\
\hline & CQ & .078 & .035 & .107 & 2.235 & .026 & .009 & 146 & 682 & 1.466 \\
\hline & TT & .073 & 037 & .084 & 1.994 & .047 & .001 & 146 & .883 & 1.132 \\
\hline & MT & .243 & .045 & 276 & 5.403 & .000 & .154 & 331 & 603 & 1.659 \\
\hline & CL & .179 & .044 & 200 & 4.061 & .000 & .092 & 266 & 652 & 1.533 \\
\hline & GB & .174 & .038 & .220 & 4.640 & .000 & 100 & 249 & .700 & 1.429 \\
\hline & SSC & 102 & .036 & .123 & 2.851 & .005 & .032 & .173 & .846 & 1.182 \\
\hline
\end{tabular}

a. Dependent Variable: YDM

Nguồn: Tính toán của tác giả

Phương trình hồi quy tuyến tính với hệ số beta chuẩn hóa từ bảng trên có dạng:

$\mathrm{Y} \boxplus M=0,276 * \mathrm{MT}+0,220 * \mathrm{SK}+0,220 * \mathrm{~GB}+0,200 * \mathrm{CL}+0,123 * \mathrm{SSC}+0,107 * \mathrm{CCQ}+0,084 * \mathrm{TT}$

Bảng 9 cũng cho thấy, hệ số VIF <10 (cụ thể VIF nằm trong khoảng từ 1.132 đến 1.659) thể hiện dữ liệu nghiên cứu không có hiện tượng đa cộng tuyến.

Kết quả hồi quy cũng cho phép khẳng định rằng, 7 giả thuyết của mô hình nghiên cứu đều được chấp nhận, các biến độc lập đều có tác động thuận chiều lên biến phụ thuộc (vì các hệ số beta đều>0).

\subsection{Kết luận và một số hàm ý}

\subsubsection{Kết luận}

Bằng phương pháp định lượng với kiểm định Cronbach alpha, phân tích nhân tố khám phá và phân tích hồi quy đa biến, nghiên cứu đã cho thấy, thực sự có 7 yếu tố ảnh hưởng đến ý định mua thực phẩm an toàn của người tiêu dùng ở các quận trung tâm của TP.HCM. Đó là: Thái độ đối với môi trưòng-MT $(\beta=0,276)$ có tác động mạnh nhất; thứ hai là Sụ quan tâm đến sức khỏe-SK và Nhận thức về giá bán-GB (đều có $\beta=0,220)$; thứ ba và thứ tư là Nhận thức về chất luọng- $C L \quad(\beta=0,200)$ và Sụ sã̃n có của sản phẩm$S S C(\beta=0,123)$; thứ năm là $C h u a ̂ ̉ n ~ c h u ̉ ~ q u a n-C C Q ~(\beta=0,107)$ và cuối cùng có tác động yếu nhất đến ý định mua thực phẩm an toàn là Truyền thông đại chúng-TT với hệ số $\beta=0.084$.

Kết quả trên phù hợp với kết quả nghiên cứu của các tác giả Nguyễn Phong Tuấn, Nguyễn Thanh Hương, Lê Thùy Hương, Anssi Tarkiainen và Sanna Sundqvist, Jay Dickieson và Victoria Arkus, Victoria Kulikovski và Manjola Agolli.

\subsubsection{Một số hàm ý}

Có 7 hàm ý quản trị cho doanh nghiệp sản xuất, kinh doanh thực phẩm an toàn nhằm làm tăng ý định mua của người tiêu dùng ở các quận trung tâm của TP.Hồ Chí Minh

\subsubsection{Về yếu tố thái độ đối với môi trường}

Đây là yếu tố có ảnh hưởng mạnh nhất làm nảy sinh ý định mua thực phẩm an toàn của người tiêu dùng $(\beta=0,276)$. Bởi vậy, các doanh nghiệp sản xuất và kinh doanh thực phẩm phải tìm cách chứng minh cho người tiêu dùng thấy được việc sản xuất, chế biến và chất thải từ sản phẩm của họ là an toàn đối với môi trường. Quá trình sản xuất và chế biến phải được thực hiện theo những tiêu chuẩn "sạch". Với sản xuất trồng trọt phải dùng phân hữu cơ, xác bắp, đậu tương,... đã phân hủy, tưới nuớc không bị ô nhiễm, phòng 
trừ sâu bệnh bằng các loại thiên địch... Chăn nuôi không dùng chất tăng trọng, tạo nạc, sử dụng thức ăn gia súc sạch,... Sản phẩm chế biến không dùng hóa chất, chất tạo màu, chất kết dính hoặc là các loại phụ gia độc hại, không rõ nguồn gốc, v.v...

Với việc người tiêu dùng TP.HCM quan tâm trước hết đến môi trường cũng cho thấy ý thức trách nhiệm với cộng đồng, trước hết là những người thân yêu của họ, đã tăng lên, tương ứng với trình độ phát triển kinh tế, văn hóa của thành phố.

\subsubsection{Về yếu tố sự quan tâm đến sức khỏe}

Sự quan tâm đến sức khỏe là yếu tố mạnh thứ hai làm nảy sinh sinh ý định mua thực phẩm an toàn của người tiêu dùng $(\beta=0,220)$. Vì vậy, các doanh nghiệp sản xuất, kinh doanh thực phẩm an toàn có thể thực hiện những hoạt động nhằm khơi gợi ở người tiêu dùng ý thức quan tâm đến sức khỏe. Bằng cánh thực hiện một số chương trình tư vấn về dinh dưỡng, nâng cao sức khỏe từ việc ăn uống khoa học. Và như vậy, sẽ nâng cao ý thức sử dụng thực phẩm an toàn và đẩy mạnh ý định mua của người tiêu dùng.

\subsubsection{Về yếu tố nhận thức về giá bán}

Cũng giống với yếu tố sự quan tâm đến sức khỏe, yếu tố nhận thức về giá bán là yếu tố mạnh thứ hai làm nảy sinh sinh ý định mua thực phẩm an toàn của người tiêu dùng $(\beta=0,220)$. Trong thực tế rất nhiều người tiêu dùng có cùng suy nghĩ là giá bán thấp thì sản phẩm có chất lượng thấp và không an toàn. Ngược lại, giá bán cao hơn thì sản phẩm đó có chất lượng và độ an toàn cao hơn. Chính vì vậy, các nhà sản xuất, chế biến và kinh doanh phải đưa ra một mức giá cho thực phẩm an toàn cao hợp lý. Nghĩa là giá bán phải phù hợp với khả năng chi trả của người tiêu dùng, nhưng vẫn đảm bảo cho doanh nghiệp có lãi. Muốn vậy, các doanh nghiệp phải có thông tin giá của những sản phẩm thường và an toàn cùng loại đang bán trên thị trường để quyết định mức giá bán phù hợp. Đồng thời, các doanh nghiệp cần thực hiện một chiến lược giá hợp lý để thúc đẩy mua thực phẩm an toàn của người tiêu dùng

\subsubsection{Về yếu tố nhận thức về chất lượng}

Nhận thức về chất lượng thực phẩm an toàn là yếu tố mạnh thứ ba làm nảy sinh ý định mua thực phẩm an toàn của người tiêu dùng $(\beta=0,200)$. Chất lượng và giá bán là hai chỉ tiêu khác nhau, nhưng có liên quan với nhau. Khi người tiêu dùng hài lòng với chất lượng mong muốn thì họ sẽ chấp nhận mua sản phẩm với giá bán cao hơn. Chính vì vậy, các nhà sản xuất và kinh doanh thực phẩm an toàn phải tìm cách tác động vào nhận thức của người tiêu dùng về chất luợng thực phẩm của họ là tốt, sạch và có chất lượng cao hơn so với các loại thực phẩm thường. Nếu việc làm này được tiến hành thường xuyên và có minh chứng về đảm bảo chất luợng, chắc chắn sẽ nảy sinh ý định mua thực phẩm an toàn của người tiêu dùng tại thành phố Hồ Chí Minh.

\subsubsection{Về yếu tố sự sẵn có của thực phẩm an toàn}

Đây là yếu tố mạnh thứ tư có ảnh hưởng đến ý định mua thực phẩm an toàn của người tiêu dùng với $\beta=0,123$. Nhiều khi người tiêu dùng có tiền, nhưng vì việc bố trí các cửa hàng, siêu thị có thực phẩm an toàn không hợp lý, vị trí để thực phẩm an toàn tại những nơi này không thuận tiện, thì có thể người tiêu dùng từ bỏ ý định mua. Vì vậy, việc xác định vị trí mở cửa hàng, siêu thị bán thực phẩm an toàn phải phù hợp. Đảm bảo gần khu dân cư, khu công nghiệp và các trường học. Đồng thời quan tâm hơn nữa đến sự bắt mắt của bao bì đóng gói, vị trí trưng bày thực phẩm an toàn trong các cửa hàng, siêu thị để sao cho người mua dễ thấy, dễ tìm. Từ đó, họ mới nảy sinh ý định mua. Muốn xác định chính xác vị trí đặt siêu thị, cửa hàng nói chung, bán thực phẩm an toàn nói riêng, cần giải bài toán vận trù học về xác định địa điểm.

\subsubsection{Về yếu tố chuẩn mực chủ quan}

Yếu tố chuẩn mực chủ quan có ảnh hưởng mạnh thứ năm đến nảy sinh ý định mua thực phẩm an toàn của người tiêu dùng với $\beta=0,107$. Thực tế đã chỉ ra rằng, nhận thức về sự an toàn của thực phẩm thông qua truyền miệng có ảnh hưởng đến người tiêu dùng. Bởi vậy, nếu nhận biết bà con, bạn bè, đồng nghiệp và những người khác đã sử dụng thực phẩm an toàn, chắc chắn người tiêu dùng sẽ "a dua" nảy sinh ý định mua. Để thông tin truyền miệng đến được với nguời tiêu dùng, doanh nghiệp cần thúc đẩy các hoạt động cộng đồng nhằm thông tin về lợi ích của thực phẩm an toàn. Đồng thời cho người tiêu dùng thấy được xu hướng của xã hội về việc sử dụng thực phẩm an toàn. Từ đó, thông tin được lan truyền đến người tiêu dùng, kể cả người tiêu dùng chưa mấy quan tâm đến thực phẩm an toàn. Kết quả là sẽ hình thành một xu hướng ứng xử mới, làm tăng ý định mua thực phẩm an toàn 


\subsubsection{Về yếu tố truyền thông đại chúng}

Nghiên cứu đã chỉ ra rằng, đây là yếu tố có ảnh hưởng yếu nhất đến ý định mua thực phẩm an toàn vì $\beta=0,084$. Truyền thông đại chúng có tác động tích cực tới ý định mua thực phẩm an toàn. Bởi vậy, doanh nghiệp, trong đó có các doanh nghiệp sản xuất và kinh doanh thực phẩm an toàn cần sử dụng hợp lý các phương tiện để truyền đi những thông tin về sản phẩm của mình nhằm hình thành nên thái độ tích cực và dẫn đến hành vi mua thực phẩm an toàn. Tuy nhiên, các thông tin đại chúng, nhất là thông tin mạng, rất khó để kiểm chứng tính chính xác, đặc biệt là thông tin từ các sản phẩm mang tính nhạy cảm như đối với thực phẩm an toàn. Vì vậy, sự hoài nghi luôn tồn tại. Điều này cũng giải thích vì sao truyền thông đại chúng có ảnh hưởng yếu hơn so với thông tin "truyền miệng" trong việc hình thành ý định mua thực phẩm an toàn của người tiêu dùng.

\section{HAN CHẾ VÀ HƯỚNG NGHIÊN CÚU TIẾP THEO}

\subsection{Hạn chế}

Hạn chế của nghiên cứu là việc lấy mẫu theo phương pháp chọn mẫu thuận tiện, phi xác suất và kích thước mẫu chưa lớn. Thêm nữa, thông tin thu thập cho nghiên cứu chỉ được thực hiện tại một số quận ở trung tâm thành phố. Vì vậy, các hàm ý quản trị chưa mang tính phổ quát cho cả TP.Hồ Chí Minh.

\subsection{Hướng nghiên cứu tiếp theo}

Tăng cường tính đại diện của mẫu nghiên cứu bằng cách tăng kích thước mẫu và lấy mẫu trên tất cả các quận, huyện của thành phố theo tỷ lệ dân số. Đồng thời đưa thêm vào mô hình nghiên cứu một số yếu tố, biến kiểm soát mới. Kết quả là các hàm ý quản trị sẽ có tính phổ quát cao hơn cho cả thành phổ Hồ Chí Minh.

Mặt khác, cũng rất cần nghiên cứu mối quan hệ giữa ý định mua với hành vi mua. Vì rằng, việc có ý định mua với việc thực hiện hành vi mua thực phẩm an toàn của người tiêu dùng là hai mặt của cùng một vấn đề.

\section{TÀI LIỆU THAM KHẢO}

[1] Luật An toàn thưc phẩm (số 55/2010/QH12), năm 2010

[2] Ajen I. and Fishbein M. (1975). Belief, Attitude, Intention and behavior. An introductiion to theory and research. Reading, Mass: Addion-Wesley

[3] Ajen I. (1991). "Th theory of planed behavior" Organizational Behavior and Human Decision Processes. Vol 50, pp. 179-211.

[4] Lê Thùy Hương (2014). Luận án tiến sĩ. Trường Đại học Kinh tế quốc dân

[5] Nguyễn Đình Thọ (2011). Phuoong pháp nghiên cưu khoa học trong kinh doanh. Nhà xuất bản Lao động Xã hội, Hà Nội.

[6] Hoàng Trọng và Chu Nguyễn Mộng Ngọc (2008). Phân tích dũ liệu nghiên cúu SPSS. Nhà xuất bản Thống kê.

[7] Vũ Huy Thông (2010), "Giáo trình Hành vi người tiêu dùng” NXB Đại học Kinh tế quốc dân, Hà Nội.

[8] Han, H., Hsu, LT., and Lee, JS. (2009), “ Empirical Investigation Of The Roles Of Attitudes Towards Green Behaviors, Overall Image, Gender, And Age In Hotel Customers' Eco-friendly Decision-making Process”,

[9] Essoussi, L.H. và Zahaf, M. (2008), "Decision making process of community organic food consumers: an exploratory study”, Journal of Consumer Marketing, Vol. 25 No. 2, pp. 95-104.

Ngày nhận bài: 28/02/2018 Ngày chấp nhận đăng: 20/6/2018 